УДК 622.276 .53

\title{
ТЕПЛООБМЕННОЕ УСТРОЙСТВО ДЛЯ ПОГРУЖНЫХ ЭЛЕКТРОДВИГАТЕЛЕЙ УСТАНОВОК ЭЛЕКТРОЦЕНТРОБЕЖНЫХ НАСОСОВ
}

\author{
Вахитова Роза Ильгизовна', \\ roza-w@mail.ru \\ Уразаков Камил Рахматуллович2, \\ UrazakK@mail.ru
}

Думлер Елена Борисовна²,
dumler08@mail.ru

1 Альметьевский государственный нефтяной институт, Россия, 423450, г. Альметьевск, ул. Ленина, 2а.

2 Уфимский государственный нефтяной технический университет, Россия, 450062, г. Уфра, ул. Космонавтов, 1.

\begin{abstract}
Актуальность разработки технического устройства обусловлена необходимостью решения задач, связанных с охлаждением высокооборотных вентильных и асинхронных погружных двигателей, в том числе при выводе добывающих скважин на рабочий режим. Особенно актуальна разработка эфффективных систем охлаждения таких двигателей при использовании высокооборотных двигателей в малодебитных скважинах, поскольку мощность источников теплоты резко увеличивается по квадратичному закону в зависимости от числа оборотов.

Основная цель: разработать конструкцию теплообменного устройства, позволяющего интенсифицировать теплообменные процессы в погружном электродвигателе для увеличения его межремонтного периода работы.

Объектом исследования является модуль-теплообменник, применяемый в серийно выпускаемых электропогружных центробежных насосных установках с асинхронными погружными маслозаполненными двигателями и в высокоборотных погружных установках с вентильными электродвигателями. Модуль-теплообменник предназначен для снижения тепловой напряженности, повышения его эфффективности при работе в условиях воздействия высоких температур.

Методы. Для решения поставленной задачи был использован метод проектных исследований путем модернизации существующей конструкции модуля-теплообменника с низкой эфффективностью теплообмена между пластовой жидкостью и нагретьм маслом в электродвигателе с небольшими перепадами температур между ними.

Результаты. Предложена усовершенствованная конструкция модуля-теплообменника, которая в условиях мальх внутренних габаритов скважины и относительно невысоких температурных градиентов между нагретым маслом погружного электродвигателя и омывающей его пластовой жидкостью позволяет обеспечить максимальную степень интенсификации теплообменных процессов. Для эффрективного охлаждения маслосистемы электродвигателя предложено использовать двухконтурную систему охлаждения. Для увеличения общей площади поверхности активного теплообмена выполнено оребрение внутреннего канала сквозного протока пластовой жидкости. Для обеспечения активной циркуляции нагретого масла предложено на поверхности внутренних стенок маслоканалов установить элементы закрутки потока, позволяющие выровнять температурные показатели пластовой жидкости и масла.
\end{abstract}

\section{Ключевые слова:}

Электроцентробежная насосная установка, погружной электродвигатель, теплообменник, теплообменный процесс, температурный градиент.

\section{Введение}

На нефтедобывающих предприятиях Западной Сибири основным оборудованием являются установки электроцентробежных насосов (УЭЦН). В последнее время для повышения эффективности добычи нефти применяют высокооборотные регулируемые электродвигатели (более 3000 об/мин). Использование высокооборотных двигателей в качестве привода УЭЦН дает возможность, не изменяя габариты основных рабочих органов, увеличить напор ступени, снизить массогабаритные характеристики установки и облегчить вывод насосной установки на режим $[1,2]$.

Существенным фактором, осложняющим добычу нефти, является влияние высоких температур пластовой жидкости. Этот фактор способствует преждевременному выходу погружного двигателя (ПЭД) и кабельной линии из строя [3-6]. Можно выделить ряд параметров, оказывающих влияние на тепловой режим работы УЭЦН [7-11]: потребляемая установкой мощность; температурный перепад между пластовой жидкостью и ПЭД; скорость обтекания пластовой жидкости.

Высокая температура пластовой жидкости (более $\left.100{ }^{\circ} \mathrm{C}\right)$ значительно осложняет работу погружной установки, особенно при высоких значениях подачи насоса и глубины подвески насосного агрегата. Перегрев ПЭД при таких условиях эксплуатации может достигать $40{ }^{\circ} \mathrm{C}$. При перегреве может разрушиться изоляция обмотки статора с последующим выходом двигателя из строя. Тепло, выделяющееся в погружном двигателе из-за механических и магнитных потерь в рабочих (теплонапряженных) участках двигателя, передается посредством диэлектрического масла от ПЭД к обтекающей его скважинной жидкости. 
Процесс теплоотвода происходит через наружную поверхность погружного двигателя. Температурные значения внутренних узлов погружного двигателя могут превышать отметку в $200{ }^{\circ} \mathrm{C}$. При таких условиях сокращается ресурс электродвигателя [12].

Основными причинами выхода из строя электродвигателя и кабеля из-за перегрева обмотки являются: прогар в корпусе двигателя; электропробой обмотки статора, в лобовой части токоввода кабельной линии, брони, в сростках и теле кабеля, в муфте кабельного ввода [13-15].

На современном этапе эксплуатации УЭЦН актуальными являются вопросы, связанные с охлаждением высокооборотных ПЭД при выводе добывающих скважин на рабочий режим (для таких двигателей, работающих на переменном токе, величина плотности теплового потока через наружную поверхность корпуса может достигать 30000 Вт/м²). Это обуславливается тем, что отведение теплоты от внешней поверхности погружного двигателя осуществляется в условиях естественной конвекции перекачиваемой жидкости. Разработка эффективных систем охлаждения высокооборотных двигателей особенно актуальна при использовании их в добывающих скважинах с малым дебитом, так как мощность источников тепловой энергии резко увеличивается по квадратичному закону в зависимости от числа оборотов $[16,17]$.

Имеется ряд опубликованных работ, направленных на повышение надежности работы насосных установок в осложненных условиях [18-20]. Тем не менее анализ опыта эксплуатации погружных установок показывает необходимость создания технических устройств, обеспечивающих дополнительное охлаждение погружного двигателя.

Для снижения температуры пластовой среды в рабочей зоне скважинного высокооборотного двигателя актуально использование отдельных модулейтеплообменников, которые раньше практически не использовали в составе погружных двигателей. Разработка такого оборудования потребует новых конструкторских оригинальных решений, позволяющих максимально интенсифицировать теплообменные процессы между нагретым маслом внутри двигателя и пластовой жидкостью, омывающей двигатель.

\section{Конструкторская проработка}

Теплообменники, как правило, используют для снижения тепловой напряженности в погружных маслозаполненных электродвигателях, приводящих в действие электропогружные центробежные насосы в нефтяных скважинах, особенно в малодебитных.

В работе [19] рассмотрена система для охлаждения ПЭД, в которой циркулирующее диэлектрическое масло передает теплоту корпусу статора и в результате этого тепловая энергия передается скважинной жидкости, окружающей погружной двигатель. Предложенная система охлаждения является недостаточно эффективной, поскольку передача теплоты к скважинной жидкости происходит через активный участок поверхности малой площади в радиальном направлении, а увеличить контактирующую с маслом площадь боковой поверхности статора не представляется возможным.

Известна конструкция теплообменника ПЭД с оребрением [20], недостатком которого является низкая эффективность теплообменных процессов между нагретым маслом и скважинной жидкостью, особенно при малых температурных градиентах.

Для повышения эффективности работы скважинного теплообменного устройства погружного электродвигателя и ресурса высокооборотного ПЭД, особенно при эксплуатации в скважинах с малым дебитом на базе теплообменника, содержащего оребрение, разработан усовершенствованный модуль-теплообменник. Состав оборудования УЭЦН, укомплектованной теплообменным устройством, названным модулемтеплообменником, представлен на схеме (рис. 1).

В скважине теплообменное устройство устанавливается под электродвигателем погружного насосного агрегата, состоящего из многосекционного электроцентробежного насоса, газосепаратора и гидрозащиты. Устье скважины обвязано арматурой. От станции управления проложена кабельная линия, питающая электродвигатель.

Погружной электродвигатель заполнен жидким теплоносителем, в качестве которого используют синтетическое масло. При работе погружного двигателя в его теплонапряженных зонах, а именно в статоре, роторе, осевых опорах, выделяется теплота, которая передается циркулирующему в полости двигателя маслу.

Принципиальная схема модуля-теплообменника представлена на рис. 2. Модуль-теплообменник выполняется в двухконтурном исполнении. Нагреваясь в электродвигателе, масло направляется на прием модуля-теплообменника через входные отверстия первого контура - 1 верхнего модуля - 11. Затем масло по приемному маслоканалу - 2 движется через отверстия переходного маслоканала - 3 и перетекает в маслоотводящие каналы - 5-8. На внутренней цилиндрической поверхности стенок маслоканала - 5 выполнены выступающие элементы закрутки потока - 4, представляющие собой проволоку, навитую по спирали. Элементы закрутки потока - 4 закручивают поток нагретого масла. Закрутка потока является эффективным методом интенсификации теплообменных процессов. В маслоканале - 5 происходит передача тепловой энергии через стенки модулятеплообменника от масла к пластовой жидкости, перемещающейся по каналу - 10 (поток А второго контура) и омывающей внешнюю поверхность модулятеплообменника. Маслоканал - 6 связан с маслоканалом - 5 поворотным каналом для масла - 7. Маслоканал - 8 пропускает масло (поток В первого контура) в маслоканал нижнего модуля - 16 через щелевые отверстия - 15 и обратный маслоканал -13 . Обратный маслоканал - 13 с щелевыми отверстиями - 15 представляет собой цилиндрический элемент на оси модуля-теплообменника и обеспечивает возможность охлажденному маслу переместится в зону двигателя, где происходит активное выделение тепла. 


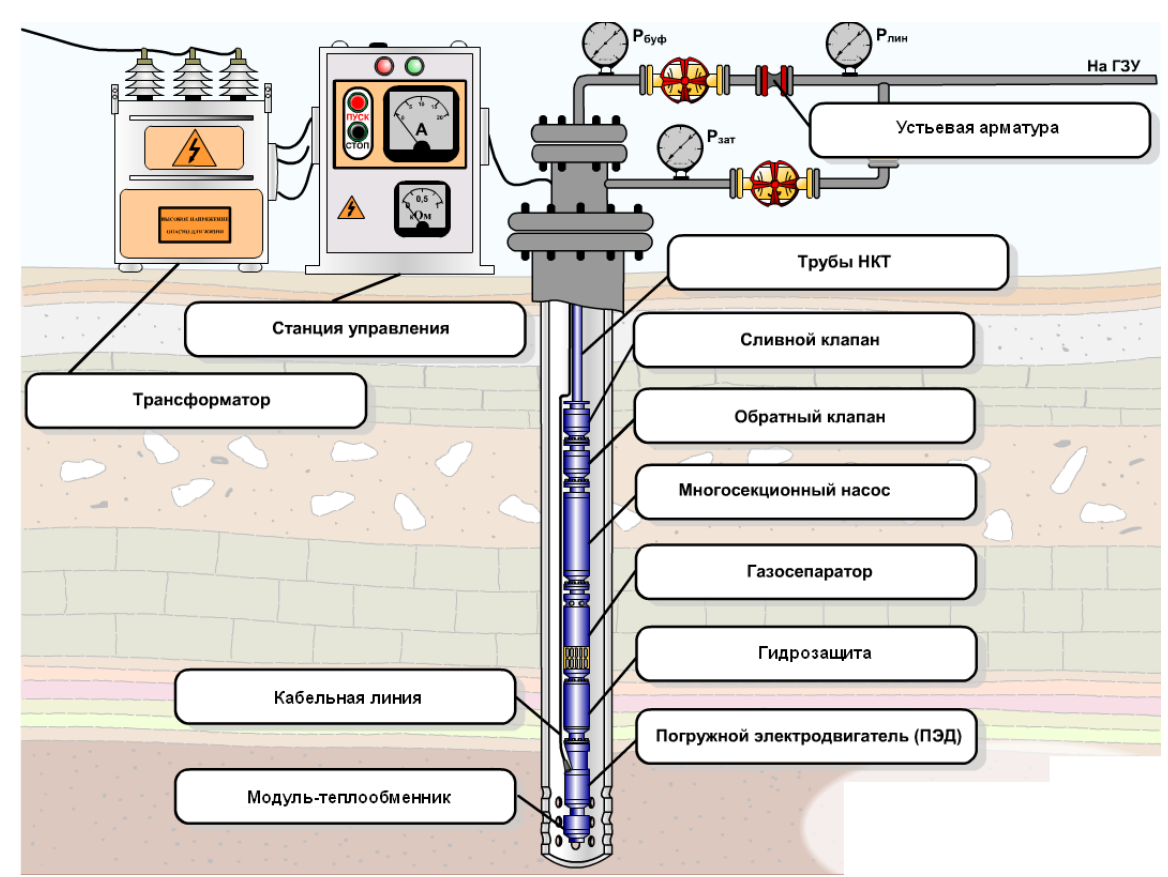

Pис. 1. Схема расположения установки электропогружного иентробежного насоса в скважине

Fig. 1. Layout of the installation of an electric submersible centrifugal pump in the well

Модуль-теплообменник состоит из верхней - 11 и нижней - 16 части, присоединенных с помощью шпилек - 9 (рис. 2). Пластовая среда через входные отверстия второго контура - 14 поступает в канал сквозного протока -10 , имеющегося в верхнем -15 и в нижнем - 16 модулях. Канал сквозного протока - 10 предназначен для потока пластовой жидкости В и характеризуется теплопередающей активной поверхностью благодаря выполненному внутреннему оребрению -12.

Радиальная, осевая и тангенциальная составляющие скоростей вихревых потоков в проточных маслоканалах и их соизмеримость формируют трехмерное поле давления с радиальным градиентом, которое по величине сравнимо с продольным. Наличие поперечных составляющих скорости закрученного потока позволяет усилить конвективный теплоперенос в маслоканалах 5 и 6 , при этом в них изменяется вихревая структура закрученных потоков.

Pис. 2. Модуль-теплообменник: 1 - входное отверстие первого контура; 2 - маслоканал приемный; 3 отверстие переходного маслоканала; 4 - элемент закрутки потока; 5-8 - маслоотводящие каналь; 9 - соединение крепежное; 10 - канал сквозного протока; 11, 16 - верхний и нижний модули; 12 - оребренние; 13 - маслоканал обратный; 14 - входное отверстие второго контура; 15 - щелевые отверстия

Fig. 2. Heat exchanger module: 1 - primary circuit inlet; 2 - receiving oil channel; 3 -opening of the transition oil channel; 4 -flow swirling element; 5-8-oil drainage channels; 9 - fastening connection; 10 channel of the through duct; 11, 16 - upper and lower modules; 12 - ribbing; 13 - return oil channel; 14 - inlet of the second circuit; 15 - holes slotted

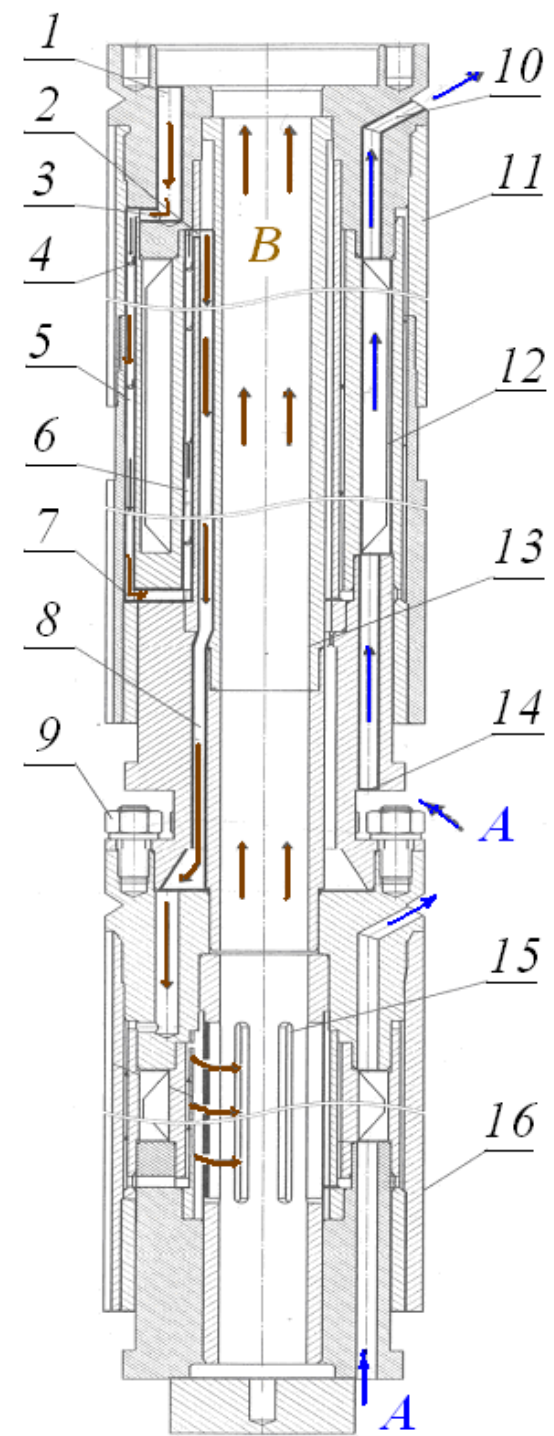


Предлагаемая усовершенствованная конструкция модуля-теплообменника позволяет в стесненных условиях скважины и при относительно малом температурном градиенте, не превышающем $40{ }^{\circ} \mathrm{C}$, между нагретым диэлектрическим маслом и пластовой жидкостью обеспечить максимальную степень интенсификации теплообменных процессов, а именно:

- использование канала сквозного протока дает возможность реализовать наиболее эффективные схемы теплообменных процессов с нагретым диэлектрическим маслом из погружного двигателя. Применение внутреннего оребрения - 12, находящегося во внутреннем канале сквозного протока жидкости - 10, увеличивает общую площадь поверхности активного теплообмена;

- общая циркуляция жидкости при закрутке потока нагретого масла элементами закрутки потока -4 , установленными на поверхности внутренних стенок маслоканалов - 6 и 8, благоприятно влияет на процесс выравнивания температурных показателей пластовой жидкости и масла, тем самым усиливая теплообменные процессы;

- пространственное извилистое течение нагретого масла по маслоканалам - 5-8 позволяет интенси-

\section{СПИСОК ЛИТЕРАТУРЫ}

1. Горлов А.Е., Деньгаев А.В. Повышение энергоэффективности эксплуатации обводненных скважин высокооборотными насосными установками // Инженер-нефтяник. - 2020. № 2. - C. 39-45.

2. Стыскин А.В., Уразбахтина Н.Г. Принципы применения вентильных электродвигателей в установках погружных электроцентробежных насосов для нефтедобывающих скважин // Электротехнические и информационные комплексы и системы. - 2013. - Т. 9. - № 3. - С. 19-23.

3. Abulfaz H.I., Malik A.S. Evaluation of the inter-repair operation period of electric submersible pump units // Eureka: Physics and Engineering. - 2020. - V. 2020 - № 1. - P. 79-86. DOI: $10.21303 / 2461-4262.2020 .001105$

4. Hemandez-Solis A., Carlsson F. Diagnosis of submersible centrifugal pumps: a motor current and power signature approaches // EPE Journal (European Power Electronics and Drives Journal). 2010. - V. 20. - № 1. - P. 58-64.

5. Энергопотребление установок погружных электроцентробежных насосов / Р.И. Вахитова, К.Р. Уразаков, Е.Б. Думлер, Д.А. Сарачева, Л.Р. Загитова // Монография. - Альметьевск: АГНИ, 2020. - $100 \mathrm{c}$

6. Кудряшов С.И. Повышение надежности погружных систем УЭЦН на примере опыта эксплуатации в ОАО «Юганскнефтегаз» // Нефтяное хозяйство. - 2005. - № 6. - С. 126-127.

7. Novel experimental device to monitor the ground thermal exchange in a borehole heat exchanger / C.S. Blazquez, L. Piedelobo, J. Fernandez-Hernandez, I.M. Nieto, A.F. Martín, S. Laguela, D. Gonzalez-Aguilera // Energies. - 2020. - V. 13. - № 5. P. en13051270. DOI: $10.3390 /$ en13051270

8. Вахитова Р.И. О значении изучения теплового режима в установках электроцентробежных насосов // Достижения, проблемы и перспективы развития нефтегазовой отрасли. - Альметьевск: АГНИ, 2018. - С. 90-93.

9. Rodriguez Leon J.R. Parametric study of motor/shroud heat transfer performance in an electrical submersible pump (ESP): Diss. Kand. nauk. - Rolla, 2000. - 145 p.

10. Electrical-thermal coupled calculation of a submersible motor used for deep-sea electromagnetic propeller / J. Li, J. Zou, X. Jiang, X. Fu // Digests of the 2010 14th Biennial IEEE Conference on Electromagnetic Field Computation, CEFC 2010. - Chicago, IL 2010. - P. 5481401. DOI: 10.1109/CEFC.2010.5481401 фицировать теплообменный процесс между потоками масла и пластовой жидкости, проходящей в сквозном канале - 10 при работе насосного агрегата, путем более эффективного многократного охлаждения нагретого масла;

- возможность применения нескольких модулей, установленных последовательно, позволяет кратно улучшить процесс охлаждения масла.

\section{Заключение}

Таким образом, применение модуля-теплообменника в погружных центробежных насосных установках позволит интенсифицировать теплообменные процессы и создать более благоприятный температурный режим работы погружного электродвигателя, тем самым увеличив его межремонтный период и продлив его ресурс. Предлагаемую конструкцию модулятеплообменника рекомендуется использовать не только в составе высокооборотных погружных установок, оснащенных вентильными двигателями, но и в установках с асинхронными электродвигателями для их эффективной эксплуатации в скважинах с высокой температурой пластовой жидкости.

11. Study on suppressing nonlinear chaos of electric submersible motor for identifying temperature / W. Liguo, W. Songlin, A. Tianqi, X. Dianguo // The International Conference on Technological Advances in Electrical, Electronics and Computer Engineering, $\begin{array}{llll}\text { TAEECE } & 2013 . & - & \text { P. }\end{array}$ DOI: 10.1109/TAEECE.2013.6557217

12. Сарачева Д.А., Вахитова Р.И., Уразаков К.Р. Зависимость теплового состояния электроцентробежного насоса от частоты вращения двигателя // Известия Томского политехнического университета. Инжиниринг георесурсов. - 2019. - Т. 330. № 12. - C. 103-110. DOI: 10.18799/24131830/2019/12/2406

13. Причины аварий на скважинах, оборудованных УЭЦН / Д.А. Косов, А.В. Волков, М.А. Сайфуллин, А.И. Гребенюк // Научный журнал. - 2019. - № 5 (39). - С. 31-33.

14. Бахтияров Р.Х. Осложнения при эксплуатации УЭЦН и методы повышения эффективности эксплуатации УЭЦН // Современные технологии в нефтегазовом деле-2019. - Уфа: УГНТУ, 2019. - C. 28-32.

15. Roth B.A., Xiao J.X., Paquette M. Novel electric submersible pump cable operates in high $\mathrm{H} 2 \mathrm{~S}$ production environmemt // Society of Petroleum Engineers - SPE Abu Dhabi International Petroleum Exhibition and Conference 2016. - Abu Dhabi, UAE, 2017. - P. 245-261.

16. Кириченко В.В. УЭЦН для малодебитного фонда скважин // Деловой журнал Neftegaz RU. - 2019. - № 6 (90). - С. 70-72.

17. Антропов А.В. Применение вентильных двигателей // Материалы IX Межрегиональной научно-практической конференции. - Ижевск: Ижевский институт компьютерных исследований, 2019. - С. 12-14.

18. Barzegari Bafghi M.H., Vahedi A. Investigation of start-up conditions on electric submersible pump driven with flux switching motor // Turkish Journal of Electrical Engineering and Computer Sciences. - 2019. - V. 27. - № 5. - C. 3967-6979. DOI: 10.3906/elk1811-197

19. Скважинные насосные установки для добычи нефти В.Н. Ивановский, В.И. Дарищев, А.А. Сабиров, В.С. Каштанов, С.С. Пекин. - М.: ГУП Изд-во «Нефть и газ» РГУ нефти и газа им. И.М. Губкина, 2002. - 824 с.

20. Погружной электродвигатель: пат. Рос. Федерация, № 2236742, заявл. 30.08.2002; опубл. 20.09.2004. Бюл. № 26. - 7 с

Поступила 01.03.2021 г. 


\section{Информация об авторах}

Baxитова P.И., кандидат технических наук, доцент кафедры электро- и теплоэнергетики Альметьевского государственного нефтяного института.

Уразаков К.P., доктор технических наук, профессор кафедры машин и оборудования нефтегазовых промыслов Уфимского государственного нефтяного технического университета.

Думлер E.Б., кандидат технических наук, доцент кафедры машин и оборудования нефтегазовых промыслов Уфимского государственного нефтяного технического университета. 
UDC 622.276 .53

\title{
HEAT EXCHANGE DEVICE FOR SUBMERSIBLE ELECTRIC MOTORS OF ELECTRIC CENTRIFUGAL PUMP UNITS
}

\author{
Roza I. Vakhitova ${ }^{1}$ \\ roza-w@mail.ru \\ Kamil R. Urazakov², \\ UrazakK@mail.ru \\ Elena B. Dumler², \\ dumler08@mail.ru \\ 1 Almetyevsk State Oil Institute, \\ 2a, Lenin street, Almetyevsk, 423450, Russia. \\ 2 Ufa State Oil Technical University, \\ 1, Kosmonavtov street, Ufa, 450062, Russia.
}

The relevance of the device development is caused by the need to solve the problems related to the cooling of high-speed valve and asynchronous submersible motors. The development of efficient cooling systems for such engines when using high-speed engines in lowflow wells is especially urgent, since the power of heat sources increases sharply according to a quadratic law depending on the number of revolutions.

The main aim of the research is to develop a design of a heat exchange device that allows intensifying heat exchange processes in a submersible electric motor to increase its overhaul period.

Object: a heat exchanger module for reducing thermal stress in serially produced submersible equipment of electric submersible centrifugal pump installations with asynchronous submersible oil-filled motors and high-speed submersible installations with valve motors for their efficient operation at high temperatures.

Methods. To solve the problem, the method of design study was used by modernizing the existing design of the heat exchanger with a low efficiency of heat transfer between the reservoir fluid and the heated oil of the electric motor with small temperature gradients between them.

Results. The authors have proposed the improved design of the heat exchanger module, which allows providing the maximum degree of intensification of heat exchange processes in the small internal dimensions of the well and relatively low temperature gradients between the heated oil of the submersible electric motor and the formation fluid washing it. For effective cooling of the oil system of the electric motor, it is proposed to use a two-circuit cooling system. To increase the total surface area of active heat transfer, ribbing of the internal channel of the through flow of formation fluid is made. To ensure active circulation of heated oil, it is proposed to install flow swirling elements on the surface of the inner walls of the oil channels, which allows equalizing the temperature indicators of the formation fluid and oil.

\section{Key words:}

Electric centrifugal pumping unit, submersible electric motor, heat exchanger, heat exchange process, temperature gradient.

\section{REFERENCES}

1. Gorlov A.E., Dengaev A.V. Increasing the energy efficiency of operating water-cut wells with high-speed pumping units. Petroleum Engineer, 2020, no. 2, pp. 39-45. In Rus.

2. Styskin A.V., Urazbakhtina N.G. Principles of application of valve electric motors in installations of submersible electric centrifugal pumps for oil wells. Electrical and information complexes and systems, 2013, vol. 9, no. 3, pp. 19-23. In Rus.

3. Abulfaz H.I., Malik A.S. Evaluation of the inter-repair operation period of . electric submersible pump units. Eureka: Physics and Engineering, 2020, vol. 2020, no. 1, pp. 79-86. DOI: $10.21303 / 2461-4262.2020 .001105$

4. Hemandez-Solis A., Carlsson F. Diagnosis of submersible centrifugal pumps: a motor current and power signature approaches. $E P E$ Journal (European Power Electronics and Drives Journal), 2010, vol. 20, no. 1, pp. 58-64.

5. Vakhitova R.I., Urazakov K.R., Dumler E.B., Saracheva D.A., Zagitova L.R. Energopotreblenie ustanovok pogruzhnykh elektrotsentrobezhnykh nasosov [Energy consumption of submersible electric centrifugal pump installations. Monograph]. Almetyevsk, AGNI Publ., 2020.100 p.

6. Kudryashov S.I. Improving the reliability of submersible ESP systems on the example of operating experience at OAO Yuganskneftegaz. Oil Industry, 2005, no. 6, pp. 126-127. In Rus.

7. Blazquez C.S., Piedelobo L., Fernandez-Hernandez J., Nieto I.M., Martín A.F., Laguela S., Gonzalez-Aguilera D. Novel experi- mental device to monitor the ground thermal exchange in a boreholeh heat exchanger. Energies, 2020, vol. 13, no. 5, pp. en13051270. DOI: 10.3390/en13051270

8. Vakhitova R.I. O znachenii izucheniya teplovogo rezhima $\mathrm{v}$ ustanovkakh elektrotsentrobezhnykh nasosov [On the importance of studying the thermal regime in the installations of electric centrifugal pumps]. Dostizheniya, problemy i perspektivy razvitiya neftegazovoy otrasli [Achievements, problems and prospects for the development of the oil and gas industry]. Almetyevsk, AGNI Publ., 2018. pp. 90-93.

9. Rodriguez Leon J.R. Parametric study of motor/shroud heat transfer performance in an electrical submersible pump (ESP). Cand. Diss. Rolla, 2000. 145 p.

10. Li J., Zou J., Jiang X., Fu X. Electrical-thermal coupled calculation of a submersible motor used for deep-sea electromagnetic propeller. Digests of the $201014^{\text {th }}$ Biennial IEEE Conference on Electromagnetic Field Computation, CEFC 2010. Chicago, IL, 2010. pp. 5481401. DOI: 10.1109/CEFC.2010.5481401

11. Liguo W., Songlin W., Tianqi A., Dianguo X. Study on suppressing nonlinear chaos of electric submersible motor for identifying temperature. The International Conference on Technological Advances in Electrical, Electronics and Computer Engineering, TAEECE. 2013. pp. 172-177. DOI: 10.1109/TAEECE.2013. 6557217

12. Saracheva D.A., Vakhitova R.I., Urazakov K.R. Dependence of the thermal state of the electric centrifugal pump on the engine speed. Bulletin of the Tomsk Polytechnic University. Geo Assets 
Engineering, 2019, vol. 330, no. 12, pp. 103-110. In Rus. DOI: $10.18799 / 24131830 / 2019 / 12 / 2406$

13. Kosov D.A., Volkov A.V., Sayfullin M.A., Grebenyuk A.I. Causes of accidents at wells equipped with ESP. Scientific journal, 2019, no. 5 (39), pp. 31-33. In Rus.

14. Bakhtiyarov R.Kh. Oslozhneniya pri ekspluatatsii UETSN i metody povysheniya effektivnosti ekspluatatsii UETSN [Complications during ESP operation and methods of increasing the efficiency of ESP operation]. Sovremennyye tekhnologii v neftegazovom dele2019 [Modern technologies in oil and gas business-2019]. Ufa, UGNTU Publ., 2019. pp. 28-32.

15. Roth B.A., Xiao J.X., Paquette M. Novel electric submersible pump cable operates in high $\mathrm{H} 2 \mathrm{~S}$ production environmemt. Society of Petroleum Engineers - SPE Abu Dhabi International Petroleum Exhibition and Conference 2016. Abu Dhabi, UAE, 2017. pp. 245-261.

16. Kirichenko V.V. ESP for marginal well stock. Business magazine Neftegaz RU, 2019, no. 6 (90), pp. 70-72. In Rus.

17. Antropov A.V. Primenenie ventilnykh dvigateley [Application of valve motors]. Materialy IX Mezhregionalnoy nauchno-

\section{Information about the authors}

Roza I. Vakhitova, Cand Sc., associate professor, Almetyevsk State Oil Institute.

Kamil R. Urazakov, Dr. Sc., professor, Ufa State Oil Technical University.

Elena B. Dumler, Cand Sc., associate professor, Ufa State Oil Technical University. prakticheskoy konferentsii [Proceedings of the IX Interregional Scientific and Practical Conference]. Izhevsk, Izhevsk Institute of Computer Research Publ., 2019. pp. 12-14.

18. Barzegari Bafghi M.H., Vahedi A. Investigation of start-up conditions on electric submersible pump driven with flux switching motor. Turkish Journal of Electrical Engineering and Computer Sciences, 2019, vol. 27, no. 5, pp. 3967-6979. DOI: 10.3906/elk1811-197

19. Ivanovskiy V.N., Darishchev V.I., Sabirov A.A., Kashtanov V.S., Pekin S.S. Skvazhinnye nasosnye ustanovki dlya dobychi nefti [Downhole pumping units for oil production]. Moscow, State Unitary Enterprise Publ. House «Oil and Gas» Russian State University of Oil and Gas named after I.M. Gubkin, 2002. 824 p.

20. Devlikanov V.M., Ivanov A.A., Ovodkov O.A., Cheremisinov E.M. Pogruzhnoy elektrodvigatel [Submersible motor]. Patent RF, no. 2236742, 2004.

Received: 1 March 2021. 